\title{
Tuberculosis Testicular: Reporte de un Caso
}

\section{Testicular Tuberculosis: Case Report}

\author{
Lilian Barandica ${ }^{1}$ Boris Cabrera ${ }^{1}$ Bernarda Soraya Cuadrado ${ }^{2}$ \\ ${ }^{1}$ Grupo de Investigación en Micobacterias, Facultad de Medicina, \\ Address for correspondence Lilian Barandica, PhD, Grupo de \\ Universidad de Cartagena, Colombia \\ ${ }^{2}$ Médico, Máster en Microbiología, Facultad de Medicina, \\ Universidad de Cartagena, Colombia \\ Investigación en Micobacterias, Facultad de Medicina, Universidad de \\ Cartagena, C. Director del grupo, Colombia \\ (e-mail: Ibarandicac@unicartagena.edu.co).
}

Urol Colomb 2019;28:56-60.

\section{Resumen \\ Palabras Clave \\ - tuberculosis pulmonar \\ - tuberculosis testicular \\ - inflamación granulomatosa}

La tuberculosis es una enfermedad infectocontagiosa emergente con alta morbimortalidad a nivel mundial tanto en su forma pulmonar como extrapulmonar. De hecho, las formas extrapulmonares a pesar de manifestarse en menor porcentaje, permiten la diseminación de la infección a numerosos órganos blanco incluyendo, el sistema genitourinario. Se presenta el caso de un paciente masculino de 50 años de edad, que consulta por presentar masa dolorosa en testículo derecho de aproximadamente 1 mes de evolución, con salida de material purulento fétido y persistente en hemiescroto, sin respuesta al tratamiento antimicrobiano ambulatorio, acompañado de disnea e hipoventilación en campo pulmonar izquierdo, y antecedente de pérdida de peso y tos con expectoración color verde a café desde hace 6 meses. Es sometido a orquiectomía radical más escrotatectomía observándose por los estudios patológicos y histoquímicos del tejido, una inflamación crónica granulomatosa con necrosis caseosa central y positiva a la coloración de Ziehl Nielssen. Por los hallazgos de la patología más los clínicos e imagenológicos a nivel pulmonar, se hace diagnóstico de tuberculosis pulmonar con diseminación a testículo y escroto. El paciente es sometido a tratamiento antifímico con mejoría.

Tuberculosis is an emerging infectious contagious disease with high morbidity and mortality worldwide both in its pulmonary and extrapulmonary forms. In fact, extrapulmonary forms, despite manifesting themselves in lesser percentage, allow the dissemination of infection to numerous target organs including, the genitourinary system. We present the case of a 50-year-old male patient, who consults for painful mass in the right testicle of approximately 1 month of evolution, with a leakage of fetid and persistent purulent material in hemiescrotum, without response to outpatient antimicrobial treatment, accompanied by dyspnea and hypoventilation in the left lung field, and a history of weight loss and cough with expectoration from green to brown for 6 months. He underwent radical orchiectomy plus scro- toctenomy. Chronic and granulomatous inflammation with central caseous necrosis and positive to the coloration of Ziehl Nielssen were observed by pathological and histochemical tissue studies. For the findings of the pathology plus the clinical and imaging findings at the pulmonary level, a diagnosis of pulmonary tuberculosis with spread to the testicle and scrotum is made. The patient undergoes antifimic treatment with improvement. received

April 2, 2017

accepted

November 2, 2017

published online

May 2, 2018
DOI https://doi.org/

$10.1055 / \mathrm{s}-0038-1648212$.

ISSN 0120-789X.

eISSN 2027-0119.
Copyright (c) 2019, Sociedad Colombiana License terms de Urología. Publicado por Thieme Revinter Publicações Ltda., Rio de Janeiro, Brazil. Todos los derechos reservados.

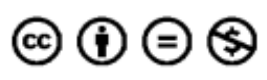




\section{Introducción}

La tuberculosis (TB) es una enfermedad infectocontagiosa causante de altos índices de mortalidad a nivel mundial. En 2014, la Organización Mundial de la Salud (OMS), reportó que 9,6 millones de personas enfermaron y 1,5 millones murieron por $\mathrm{TB}^{1}$ y en particular en el Distrito de Cartagena - Colombia, ha aumentado el número de casos diagnosticados en los últimos años. Durante los años 2007 al 2015 se observó un incremento anual en el número de casos detectados de tuberculosis en todas sus formas, subiendo la incidencia de 20 a 27 casos por cada cien mil habitantes. De igual manera también se observó un aumento anual en el número de casos de coinfección con virus de inmunodeficiencia humana (VIH) en relación al año 2007 pasando del 4,5\% al 13\% en 2013, 15,4\% en 2014 y 21\% en 2015 con presentación tuberculosis-diabetes baja (3,6\%). No obstante, frente a la incidencia nacional que es de 24,2 por cada cien mil habitantes, el distrito de Cartagena sigue ubicándose como de riesgo intermedio $(26,9 \times 100000)$ para la infección tuberculosa. ${ }^{2-4}$ Existen múltiples factores de riesgo que contribuyen a su mantenimiento en la población y que a su vez dificultan el control de la transmisión, siendo específicos del contexto sociocultural, ambiental y salud pública de la región, influenciados por el VIH y la población fluctuante, desnutrición y falta de higiene.,

Algunos pacientes asintomáticos pueden sufrir una reinfección por micobacterias, reactivación de la enfermedad latente o progresión directa de las lesiones primarias ${ }^{1}$ y en ocasiones un solo órgano es afectado, como en el caso que se describe, el testículo. ${ }^{7}$ La TB comienza casi invariablemente en el epidídimo y puede diseminarse hacia los testículos, recordando las reacciones morfológicas clásicas de la inflamación granulomatosa caseificante característica de la enfermedad. ${ }^{8}$ La presentación clínica varía desde un cuadro asintomático hasta una tumoración con respuesta inflamatoria sistémica, realizándose el diagnóstico diferencial con las neoplasias tanto benignas como malignas, confirmándose con un estudio histopatológico y cultivo. El tratamiento estándar son los antifímicos, sin embargo, en los casos de crecimiento testicular excesivo, la orquiectomía está recomendada por el riesgo de torsión testicular. ${ }^{9}$ De hecho, la TB genitourinaria comparte la patogenia con el resto de los órganos; también suele originarse como consecuencia de la diseminación de un foco renal a través de la orina, aunque el origen hematógeno también es posible, dado que aproximadamente un $11 \%$ de las TB genitales en varones no presentan focos renales. A través de una siembra hematógena, los bacilos llegan a los riñones, afectándolos casi siempre de forma bilateral, aunque el síndrome clínico sólo se manifieste en uno de ellos. La extensión al resto del sistema urinario se produce por diseminación a través de la orina contaminada, afectando a uréteres y vejiga ${ }^{7}$ siendo uno de los sistemas más afectados, con un $15 \%$ a $20 \%$ de los casos extrapulmonares. Entre el $4 \%$ y el $8 \%$ de los eventos de TB pulmonar activa, desarrollan la infección genitourinaria significativa, encontrándose que el $25 \%$ tiene historia conocida de TB pulmonar y hasta del 20\% al 50\% evidencia radiológica de infección pulmonar subclínica. ${ }^{8}$ En Colombia, el compromiso tuberculoso del sistema genitourinario de calcula en $3,9 \%$ de los casos extrapulmonares. $^{10}$

\section{Descripción del Caso}

Paciente de 50 años de edad quien consulta por presentar masa dolorosa en testículo derecho de aproximadamente 1 mes de evolución, con salida de material purulento fétido y persistente en hemiescroto, asociado y que no había respondido al tratamiento antimicrobiano ambulatorio con Cefalosporina + aminoglucósidos a dosis plenas. $\mathrm{Al}$ momento de la consulta, refiere también, pérdida de peso y tos con expectoración color verde a café desde hace 6 meses.

$\mathrm{Al}$ ingreso, se encuentra paciente disneico e hipoventilado con ganglio en cuello y abolición del murmullo vesicular en 2/3 partes del campo pulmonar izquierdo. Al examen urológico, pene no circunciso, prepucio redundante retráctil, escroto con estroma drenando material seropurulento del lado derecho, testículo derecho endurecido, caliente. Al tacto rectal, próstata de aproximadamente 30 gramos adenomatosa de consistencia ligeramente aumentada. Se hace impresión clínica de Orquiepididimitis y sospecha de un cáncer primario de testículo sobreinfectado con metástasis pulmonar. Se hacen marcadores tumorales para cáncer de testículo que resultan negativos: AFP 1,49 UI/mL, PSA: 2,66 ng/mL, fosfatasa alcalina: 283 U/L (VR: < 270 U/L), LDH: 196, BHCG cuantitativa: 1,05 UIL/mL.

En la radiografía de tórax, se observa gran opacificación que compromete gran parte del pulmón izquierdo al igual que moteados irregulares, calcificación y signos de atrapamiento aéreo en la región parahiliar izquierda, identificándose imagen de localización posterior, por lo que se sospecha una lesión tumoral asociada a un cáncer primario en testículo.

En el TAC de tórax simple y contrastado, se aprecian opacidades mixtas en el tórax simple y en el contrastado, se observan también opacidades mixtas en los campos pulmonares, nodulares, algunas de contornos nítidos, y homogéneas, con engrosamiento septales que en el contexto clínico pueden ser por cambios secundarios, lesiones hematógenas y linfáticas, prominente loculación en pleural izquierda, hipodensa, limitada por una pared muy engrosada e irregular lo cual sugiere igualmente lesión secundaria, cambios atelectásicos en el pulmón izquierdo, en particular en el lóbulo inferior.

En sangre, se encontraron como datos positivos hemoglobina $(8,9 \mathrm{~g} / \mathrm{dL})$, hematocrito $(28,1 \%)$, proteína C reactiva $(109,02 \mathrm{mg} / \mathrm{L})$, fosfatasa alcalina (356 U/L); creatinina en sangre $(1,70 \mathrm{mg} / \mathrm{dL})$ y en el uroanálisis, al examen químico de proteínas $(10 \mathrm{mg} / \mathrm{dL}$ ) con negatividad para nitritos. Al examen microscópico de sedimento urinario, se hallaron leucocitos 8 a 10 por campo en alto poder, hematíes 45 a 50 por campo en AP, bacterias y moco: +++ , cilindros hemáticos 0 a 1 por campo en AP y de uratos amorfos ++ .

Debido a la sospecha diagnóstica de tumor testicular se somete a Orquiectomía radical más escrotatectomía parcial derecha, encontrándose macroscópicamente en testículo derecho, dos nódulos mal definidos de $2,5 \times 2 \times 1 \mathrm{~cm}$ de 


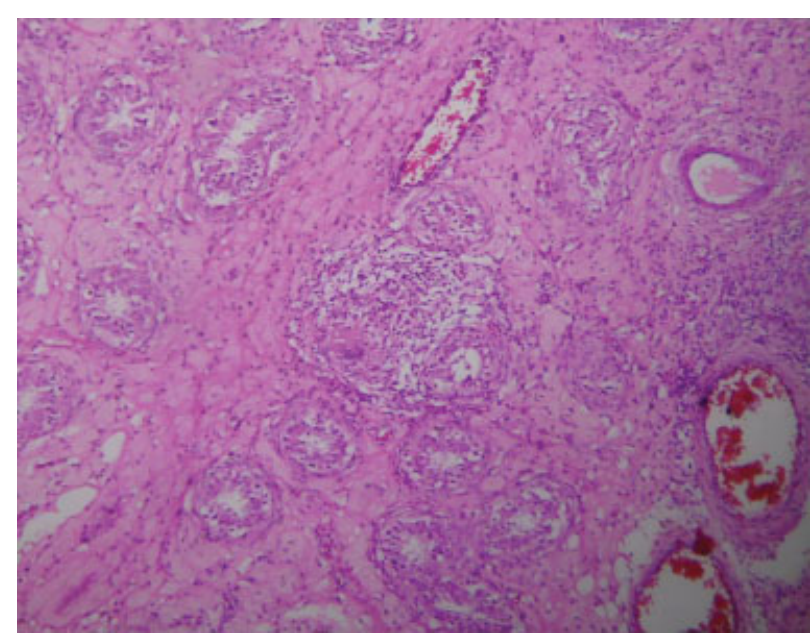

Fig. 1 Proceso granulomatoso crónico caseificante de tipo tuberculoso observado según coloración PAS.

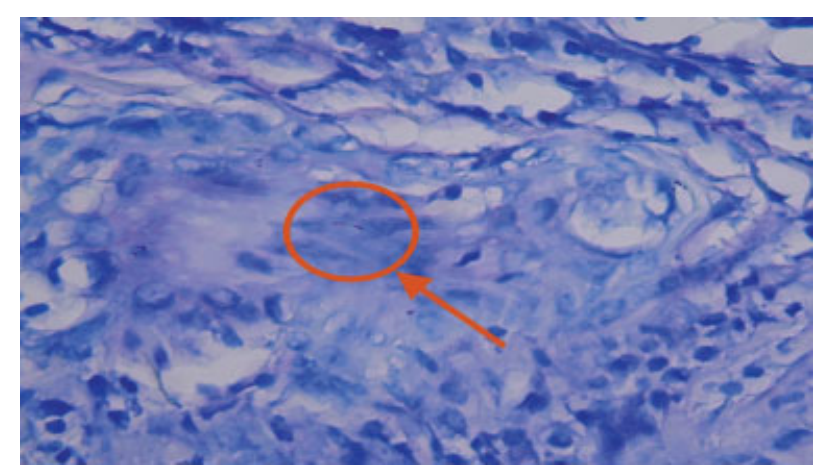

Fig. 2 Bacilos ácido alcohol resistentes (BAAR) según coloración de ZN del estudio citopatológico de testículo derecho.

color blanquecino, de consistencia firme, que ocupaban el $50 \%$ de la superficie y ubicados a un centímetro de la túnica vaginal. Parénquima testicular con histoarquitectura distorsionada por la presencia de un proceso inflamatorio crónico severo constituido por linfocitos, plasmocitos y células gigantes multinucleadas, formando granulomas con necrosis central extensa. Se observaron tubos seminíferos, algunos esclerosados, rodeados por fibrosis. Del cordón espermático, se identificó epidídimo con el mismo proceso inflamatorio no detectándose lesión tumoral en la muestra. En el escroto, piel de configuración usual y dermis con inflamación similar, siendo considerado negativo para malignidad. El reporte en resumen concluye que se trata de una inflamación crónica granulomatosa necrotizante en donde el epidídimo y piel del escroto están comprometidas por dicho proceso, recomendándose estudios complementarios de histoquímica (Ziehl Neelsen (ZN), ácido para amino ácido de Schiff (PAS) y plata metenamina de Gomori) que reportan: proceso granulomatoso crónico caseificante severo tipo tuberculoso (-Fig. 1) y la presencia de bacilos ácido alcohol resistentes (-Fig. 2).

Con los antecedentes de orquiectomía derecha, se valora el testículo izquierdo encontrando aumento de tamaño con imagen hipoecoica y área homogénea en la cara anteroposterior del testículo, se continua hacía cola del epidídimo sin clivaje relacionado con antecedentes de TB. El testículo izquierdo mide $67 \times 24 \mathrm{~mm}$. La - Fig. 3 muestra la ecografía testicular donde se descartan lesiones.

Por los síntomas respiratorios, baciloscopias seriadas de esputo positivas para bacilos ácido alcohol resistentes (BAAR) con la coloración de ZN, hallazgos radiológicos y patología a nivel testicular, se tiene alta sospecha de TBC pulmonar, se hace impresión diagnóstica de TB pulmonar con diseminación testicular y escrotal, iniciándose RIPE (rifampizina, isoniazida, pirazinamida y etambutol).

A los dos meses del tratamiento, el paciente presenta gran mejoría clínica, buena tolerancia y respuesta, ordenándose el tratamiento durante 12 meses y el control a cada 3 meses.

\section{Discusión}

En los últimos años, el número de casos reportados de TB en todas sus formas ha ido en aumento; mientras en el 2007 en Colombia se presentaban 22,5; en Cartagena se reportaban solo 19, y hasta el 2013 esa proporción se mantuvo estable, incrementándose gradualmente en el 2016 donde se encontró ligeramente mayor en el distrito de Cartagena
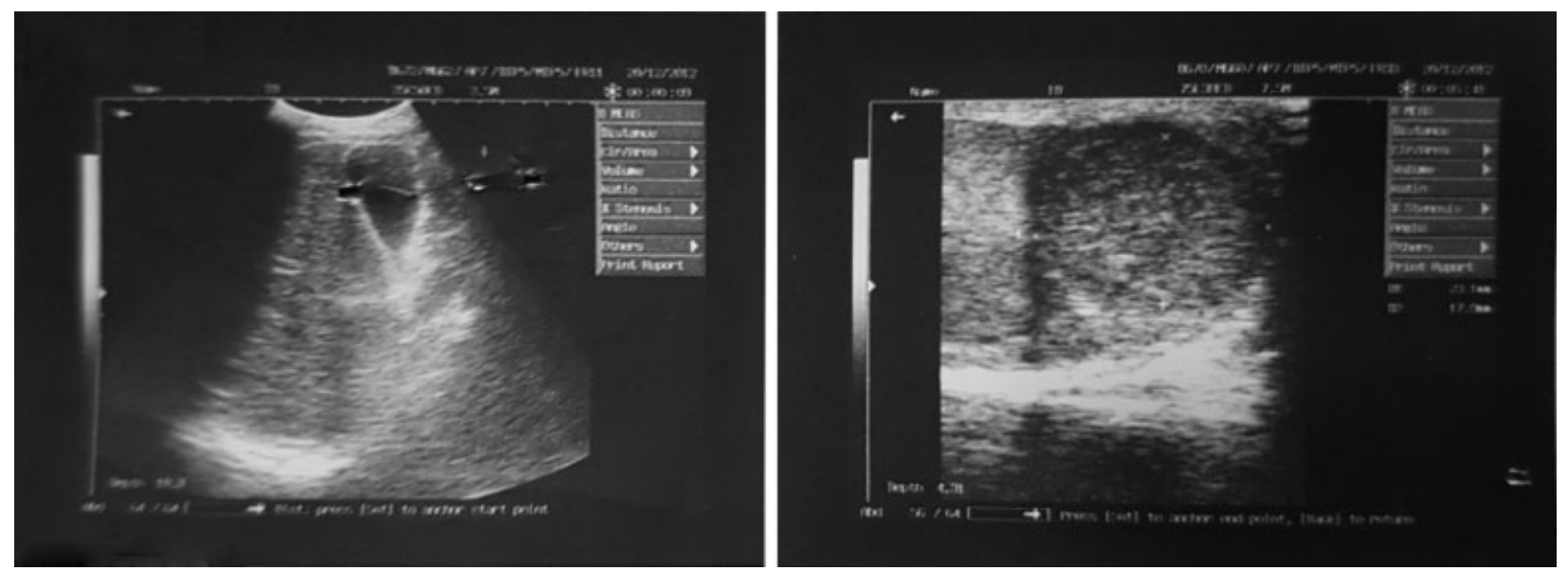

Fig. 3 Ecografía testicular. El testículo izquierdo mide $67 \times 24 \mathrm{~m}$. 
con una cifra del 28,77 comparada con los 27,9 $\times 100.000$ habitantes a nivel nacional. ${ }^{2,4}$ En el distrito de Cartagena el mayor número casos se muestra en la población masculina (64\%), siendo muy similar a la encontrada en la ciudad de Cali, donde el $60 \%$ de la población con TB son hombres, ${ }^{4}$ dato compartido en todo el territorio nacional, ${ }^{4}$ localizándose en el tracto genitourinario en el $15 \%$ de los casos y siendo el segundo sitio de diseminación extrapulmonar después del sistema linfático. ${ }^{10}$

La afectación testicular se debe principalmente, a la extensión local desde el epidídimo, siembra retrógrada y raramente por diseminación hematógena. La diseminación hematógena es más común en epidídimo y próstata debido a su abundante irrigación sanguínea. ${ }^{9}$ Los tres principales trastornos inflamatorios específicos que afectan los testículos son la epididimitis, la gonorrea y la TB lesionando casi invariablemente al epidídimo; mientras que la sífilis afecta inicialmente a los testículos. ${ }^{8}$ La TB testicular es rara, apareciendo solo en un $7 \%$ y presentándose la mayoría de las ocasiones concomitante a enfermedad pulmonar. ${ }^{7}$

El criterio de diagnóstico principal para la TB genitourinaria es el aislamiento de $M$. tuberculosis de la orina, siendo difícil de conseguir debido a la descarga urinaria esporádica de bacilos que involucra pocos microorganismos. ${ }^{8}$ La sospecha diagnóstica se debe plantear sobre los antecedentes de TB pulmonar o extrapulmonar, la sintomatología, el examen físico, el uroanálisis y el hallazgo de imágenes radiológicas anormales. El diagnóstico definitivo se logra mediante identificación del bacilo tuberculoso por baciloscopia con tinción ZN, cultivo, examen histopatológico y/o reacción en cadena de la polimerasa (PCR). ${ }^{9}$ La baciloscopia con tinción ZN es poco sensible e inespecífica en orina, no diferenciando $M$. tuberculosis de otras micobacterias; por lo que se hace necesario solicitar el cultivo en tres muestras seriadas en días diferentes con una positividad del $80 \%{ }^{10}$

La presentación clínica varía desde un cuadro asintomático hasta una tumoración con respuesta inflamatoria sistémica. El diagnóstico diferencial se debe realizar con neoplasias tanto benignas como malignas ${ }^{7}$ incluyendo otras enfermedades granulomatosas, enfermedad inflamatoria primaria, lesiones malignas, metástasis y por protozoos. Dado que las pruebas de rutina pueden ser negativas y las características de la neuroimagen no son patognomónicas, un alto índice de sospecha debe ser mantenida en pacientes de regiones de alta prevalencia de TB extrapulmonar. ${ }^{9}$

El tratamiento oportuno de la TB genitourinaria permitiría prevenir daños severos o irreversibles y a pesar que algunos autores califican el estudio histopatológico como poco sensible e inespecífico, es esencial para un correcto diagnóstico. Ante el hallazgo del contenido escrotal, con engrosamiento del epidídimo o presencia de fistula local en pacientes con síntomas constitucionales, debería incluirse la TB en el diagnóstico diferencial. En este paciente, por la clínica previa de esputo y pérdida de peso de 6 meses de evolución, debió sospecharse una TB pulmonar, lo cual sumado a la epidemiología y el encontrar una lesión a nivel del testículo, debieron ser razones de sobra para pensar en la relación entre las dos lesiones a fin de iniciar el tratamiento antifimico, sin tener que esperar al estudio histopatológico para tomar una decisión.

En este caso, el paciente recibió tratamiento acortado supervisado (TAS) por 5 meses, con evolución satisfactoria, siendo dado de alta luego de 13 días de hospitalización y seguimiento por consulta ambulatoria, sin embargo, el retardo en el diagnóstico, bien pudo haber tenido implicaciones en la función reproductiva y por qué no, emocionales del paciente.

\section{Responsabilidades Éticas}

Protección de personas y animales. Los autores declaran que para esta investigación no se han realizado experimentos en seres humanos ni en animales.

Confidencialidad de los datos. Los autores declaran que han seguido los protocolos de su centro de trabajo sobre la publicación de datos de pacientes.

Derecho a la privacidad y consentimiento informado. Los autores han obtenido el consentimiento informado de los pacientes y/o sujetos referidos en el artículo. Este documento obra en poder del autor de correspondencia.

\section{Financiación}

Los autores declaramos que el presente estudio fue ejecutado con recursos propios y no recibimos ninguna financiación.

\section{Conflicto de Intereses}

Los autores declaramos que no existen conflictos de intereses en la publicación de este trabajo y hemos seguido los protocolos establecidos en nuestra institución para la publicación de este material.

\section{Agradecimientos}

Agradecimientos especiales al personal del área de historias clínicas del Hospital Universitario y del Caribe (HUC), en especial al doctor Cesar Redondo Coordinador del Laboratorio de Patología HUC y a los residentes de patología.

\section{Bibliográfía}

1 WHO. World Health Organization. Global tuberculosis report 2015 [Internet]. 20 edition. France; 2015. Available from: www.who.int/tb/gtbr15_main_text

2 DADIS: Departamento administrativo distrital de salud - Alcaldía mayor de Cartagena. Comportamiento epidemiológico de tuberculosis en el distrito de Cartagena- periodo 11 del año 2015. 2015

3 INS. Instituto Nacional de Salud - Sivigila. Boletín epidemiológico semanal. Semana 53 del año 2015. 2015; Available from: http:// www.ins.gov.co/lineas-de-accion/subdireccion-vigilancia/sivigila/ paginas/sivigila.aspx

4 Castillo-Avila YI. Cogollo -Milanes Z, Alvis-Estrada LR. Factores asociados a la prevalencia de tuberculosis en el distrito de Cartagena. Rev Salud-UIS [Internet]. 2013;45(2):21-7. Available from: http://revistas.uis.edu.co/index.php/revistasaluduis/article/ view/3601 4. DANE: Departamento Administrativo Nacional de estadística. Boletín Técnico Pobreza Monetaria y multidimensional 
en Colombia - 2015 [Internet]. Bogotá D.C.; 2016. Available from: www.dane.gov.co/bol_15.

5 Viveiros F, Tente D, Espiridião P, Carvalho A, Duarte R. Tuberculose testicular: Caso clínico. Rev Port Pneumol 2009;15(06): 1193-1197http://linkinghub.elsevier.com/retrieve/pii/ S0873215915302014 [Internet]

6 Ogbole GI, Bassey OS, Okolo CA, Ukperi SO, Ogunseyinde AO. Testicular tuberculosis presenting with metastatic intracranial tuberculomas only: a case report. J Med Case Reports 2011;5:100

7 Mantilla JC, Cardenas N, Castellanos DA. Tuberculosis genitourinaria: reporte de 9 casos en el Hospital Universitario de Santander, Colombia, 2003-2008. Salud UIS 2009;41:181-196
8 Cabrera-Morales M, González-González K, Martínez-Rabaza M, Pérez-Suárez J, Meneses-Valencia R. Tuberculosis testicular. Presentación de un caso. In: VIII Congreso Virtual hispanoamericano de Anatomía Patológica - Octubre de 2006 [Internet]. 2006. p. 1-6. Available from: http://conganat.cs.urjc.es

9 La Torre P, Sanchez E, Agudelo C, Pardo R, Gaitan H, Gomez P. Guía de atención de tuberculosis pulmonar y extra pulmonar. Guías de promoción de la salud y prevención de enfermedades en la salud pública. Bogotá, Colombia2007:43-48

10 López-Iñiguez A, Vélez-Gómez E, Andrade-Villanueva J. Imagen clínica Tuberculosis testicular en SIDA. Rev Médica 2013;4(03): 214 